\title{
Formulation of a task to control of harmful exhaust emissions from compression ignition engine
}

This paper presents a possibility of control a harmful exhaust emissions from compression ignition engine based on computationally efficiently model of the working cycle a compression ignition engine. Parameters of the model are identified on the basis of experimental measurements carried out for a CI engine with Common Rail system. In this study is considered the control task aimed at minimization of nitrogen oxides emission for a fixed operating point of the engine.

Key words: compression ignition engine, control of exhaust emissions, numerical model

\section{Introduction}

Observed in the years 1980s significant increase in number of road going vehicles equipped with compression ignition engines and resulting from it increased negative environmental impact of harmful exhaust emissions has resulted in commenced research work on methods of restriction of harmful components from exhaust gases generated by the compression ignition engines, and at the same time on a possibilities of obtaining assumed operational parameters of the engines.

Operational parameters of the engines, including engine efficiency, thermal and mechanical loading of its components, and emission of harmful components of exhaust gases are determined by process of heat release, which depends mainly on control parameters of the engine. Introduction of microprocessor technologies and digital methods to controlling technical processes, as well as development of accumulative fuel supply systems of Common Rail type have created a new opportunities in controlling area of injection system operation in compression ignition engines, and thus controlling processes of fuel injection and heat release [5]. Modern supercharged compression ignition engines are equipped with complex systems to controlling of fuel dose and course of fuel injection, pressure of the fuel in high-pressure part of the system, injection advance angle, recirculation rate of exhaust gases, temperature and pressure of the charge in the inlet manifold and swirl of the air flowing into the cylinder. To controlling temperature and pressure of the charge are currently used turbo compressors with changing geometry of turbine, coolers of supercharged air and coolers in recirculation circuits of exhaust gases. As complementary or alternative solution is also used a throttling on the inlet system. This is accomplished by installation of air throttle in the engine inlet system, or installation of group as such throttles.

Introduction of electronically controlled Common Rail systems has enabled controlling of fuel injection process. As result, it is possible to control individual combustion phases in compression ignition engine, including phase of kinetic combustion and phase of diffusion combustion percentage of the phases of kinetic and diffusion combustion is directly related to methods how the fuel injection course is accomplished [4]. To a large degree it is possible to control the heat release course in the engine, and therefore it is possible to have effect on temperature and pressure course of the working medium in the cylinder, and on characteristic parameters of the process, such as: maximal pressure and maximal temperature of the working medium, or average indicated pressure or thermal efficiency.

\section{Concept of the controlling}

Within range of partial engine loads and under a given operational conditions exists a real possibility of selection of control parameters of the engine without change of engine torque, with simultaneous assurance of not exceeded allowable mechanical and thermal loads of engine components. Mutual correlation of fueling parameters and phenomena occurring in the engine's cylinder causes that their analysis, from engine's operational parameters point of view, including engine efficiency, thermal and mechanical load of its components, emission of harmful components of exhaust gases, requires significant amount of time and costs. To solve the above problems, therefore, a computational analysis supported by experimental research, connected with searching for optimal with a given criterion, set of control parameters is increasingly used.

Searched values of the control parameters must be possible to be attained in practice, and thus:

$$
x_{i \min } \leq x_{i} \leq x_{i \max } \text { for } \mathrm{i}=1, \ldots, r
$$

where $\mathrm{x}_{\mathrm{imin}}, \mathrm{x}_{\mathrm{imax}}$ are respectively minimal and maximal allowable values of $x_{i}$.

Limitation of the form of (1) means that searched values of control parameters should not exceed a preset boundary values, which can be different in a particular point of engine operation. For instance, allowable increase of fuel dose (and hence also its higher maximal value) will be higher for medium and high engine loads than in case when the control concerns conditions of low engine load.

The control task can be formulated in relation to all possible, or only to selected characteristic parameters with or without consideration of emission of harmful compounds of exhaust gases. In the general form, the control task can be formulated as a multi-criterion problem, in form of weighted sum of individual criteria: 


$$
\bar{\Omega}(\mathrm{X})=\sum_{\mathrm{i}=1}^{\mathrm{k}} \mathrm{C}_{\mathrm{i}}^{\mathrm{F}} \cdot \mathrm{F}_{\mathrm{i}}^{*}+\sum_{\mathrm{i}=1}^{\mathrm{q}} \mathrm{C}_{\mathrm{i}}^{\mathrm{L}} \cdot \mathrm{l}_{\mathrm{i}}
$$

where: $l_{i}$ - functionals of continuous functions $u_{i}(\varphi)$ describing courses of: mass, pressure, temperature and volume of the cylinder, $F_{i}^{*}-$ emission of $i$-th component of exhaust gases, e.g.: carbon monoxide, hydrocarbons, nitrogen oxide and smoke, $\mathrm{C}_{\mathrm{i}}^{\mathrm{F}}, \mathrm{C}_{\mathrm{i}}^{\mathrm{L}}$ - weight factors, directly connected with emission of $i$-th component and value of $i$ th functional.

The following functionals can used as the control criteria - mean indicated pressure:

$$
\mathrm{p}_{\mathrm{i}}=\frac{\int_{\mathrm{V}} \mathrm{pdV}}{\mathrm{V}_{\mathrm{s}}}
$$

where $\mathrm{V}_{\mathrm{s}}$ - swept capacity of the cylinder,

- thermal efficiency of the working cycle:

$$
\eta_{\mathrm{c}}=\frac{\int_{\mathrm{V}} \mathrm{pdV}}{\mathrm{B}_{0} \mathrm{~W}_{0}}
$$

where: $\mathrm{B}_{0}$ - fuel dose, $\mathrm{W}_{0}$ - fuel caloric value.

- maximal pressure and temperature in the cycle:

$$
\xi_{\max }=\max _{0 \leq \varphi \leq 4 \pi}\{\xi(\varphi)\}, \quad \xi \in\{p, T\}
$$

- maximal growth rate of pressure and temperature:

$$
1_{\xi}=\max _{0 \leq \varphi \leq 4 \pi}\left\{\frac{d \xi}{d \varphi}\right\}, \quad \xi \in\{p, T\}
$$

Moreover, the control task (2) is supplemented by boundary conditions having general form of:

$$
\begin{aligned}
F_{1 \min }^{*} & \leq F_{i}^{*} \leq F_{1 \max }^{*} \text { for } i=1, \ldots, k \\
l_{i \min } & \leq l_{i} \leq 1_{i \max } \text { for } i=1, \ldots, q
\end{aligned}
$$

defining respectively minimal and maximal values for each from the values important from controlling point of view.

In the control task formulated in such way, calculation of the objective function in each optimization step requires usage of the working cycle's model to evaluation of continuous functions $\mathrm{u}_{\mathrm{i}}(\varphi) \quad \varphi \in\langle 0,4 \pi\rangle$. It is necessary in each iteration, therefore, to integrate equations of the model, what requires adoption of numerically effective model of engine's working cycle.

\section{Model of the working cycle}

Requirement to ensure suitable computational efficiency of the model of the working cycle is pointing at a necessity of usage of simplified zero- or one-dimensional model. Let's consider, therefore, use of theoretical-empirical zerodimensional model proposed in the study $[2,4]$. Such type calculations model, after performed proceedings of identification of values of the model's parameters, allows to calculate characteristic parameters of the working cycle for any vector of control parameters. The model used in the controlling can be written in the general form:

$$
\mathrm{M}_{\mathrm{i}}[\mathrm{X}, \mathrm{E}, \mathrm{G}, \mathrm{p}, \mathrm{m}, \mathrm{T}]=0 \text { for } \mathrm{i}=1, \ldots, 1
$$

where: $M_{i}-$ differential operator or function, $1-$ number of equations,

together with dependencies for vector of model's parameters and vector of auxiliary parameters, respectively:

$$
\mathrm{E}=\mathrm{f}_{(\mathrm{I}, \mathrm{II})}(\mathrm{X})
$$

and

$$
\mathrm{G}=\mathrm{f}_{(\mathrm{I}, \mathrm{II})}(\mathrm{X})
$$

where $\mathrm{f}_{(\mathrm{I}, \mathrm{II})}(\mathrm{X})$ denotes mapping accomplished by neutral networks [2].

Integration of the equations describing the model leads directly to determination of the functions describing continuous courses of: mass, pressure, temperature and transient volume of cylinder, and their derivatives, what during the next step enables to determine values of individual functionals, defined in the control task in form of (2).

In scope of estimation of harmful compounds emissions like carbon monoxide, hydrocarbons, nitrogen oxide and smoke, implemented model is supplemented by relevant dependencies of the form [3]:

$$
\mathrm{F}_{\mathrm{i}}^{*}=\mathrm{f}_{\mathrm{i}}(\mathrm{X})
$$

where $\mathrm{i} \in\left\{\mathrm{CO}, \mathrm{HC}, \mathrm{NO}_{\mathrm{x}}, \mathrm{D}\right\}$.

\section{Control task}

In this study is considered the control task aimed at minimization of nitrogen oxides emission for a fixed operating point of the engine. This task therefore has the objective function in form of:

$$
\bar{\Omega}_{\mathrm{NO}_{\mathrm{x}}}(\mathrm{X})=\mathrm{C}_{\mathrm{NO}_{\mathrm{x}}}^{\mathrm{F}} \mathrm{F}_{\mathrm{NO}_{\mathrm{x}}}^{*}
$$

where coefficient $\mathrm{C}_{\mathrm{NO}_{\mathrm{x}}}^{\mathrm{F}}$ can be taken as:

$$
\mathrm{C}_{\mathrm{NO}_{\mathrm{x}}}^{\mathrm{F}}=\left[\mathrm{F}_{\mathrm{NO}_{x}, 0}^{*}\right]^{-1}
$$

where $\mathrm{F}_{\mathrm{NO}_{x}, 0}^{*}$ denotes emissions of nitrogen oxides for factory settings.

Objective of the control formulated in such way should be attained for a considered point of engine operation with simultaneous fulfillment of additional constraints, with respect to:

- not exceeded allowable emission levels of other harmful components of exhaust gases:

$$
\mathrm{F}_{\mathrm{i}}^{*} \leq \delta_{\mathrm{i}} \mathrm{F}_{\mathrm{i}, 0}^{*} \text { for } \mathrm{i} \in\{\mathrm{CO}, \mathrm{HC}, \mathrm{D}\}
$$

where $\delta_{i}$ are coefficients assigned for a given operational point of the engine, while $\mathrm{F}_{\mathrm{i}, 0}^{*}$ denotes emission or smoke of i-th component for factory settings, 
- not exceeded allowable changes in parameters of characteristic working cycle:

$$
\begin{gathered}
1_{\mathrm{i}}=\mathrm{l}_{\mathrm{i}, 0} \text { for } \mathrm{i} \in\left\{\mathrm{p}_{\mathrm{i}}\right\} \\
\gamma \mathrm{l}_{\mathrm{i}, 0} \leq \mathrm{l}_{\mathrm{i}} \text { for } \mathrm{i} \in\left\{\eta_{\mathrm{c}}\right\} \\
\mathrm{l}_{\mathrm{i}} \leq \zeta_{\mathrm{i}} \mathrm{l}_{\mathrm{i}, 0} \text { for } \mathrm{i} \in\left\{\mathrm{p}_{\max }, \mathrm{T}_{\max }\right\}
\end{gathered}
$$

where $\gamma, \zeta_{\mathrm{i}}$ are coefficients assigned for a given point of engine operation, while $l_{i, 0}$ is value of $i$-th functional (parameter of characteristic working cycle) for the initial conditions (at factory settings).

Solution of the control task formulated in form of (13) was performed for selected points of engine operation, the same as currently used by manufacturers to powering of passenger cars. Parameters of the engine are presented in the Table 1.

Table 1. The engine's technical data

\begin{tabular}{|c|c|}
\hline Engine & $\begin{array}{c}\text { Compression ignition engine supercharged by a } \\
\text { turbo compressor with direct injection equipped } \\
\text { with an electronically controlled Common Rail } \\
\text { system }\end{array}$ \\
\hline Layout of cylinders & 4 in line \\
\hline $\begin{array}{c}\text { Number of valves } \\
\text { per cylinder }\end{array}$ & 4 \\
\hline Bore & $70 \mathrm{~mm}$ \\
\hline Stroke & $82 \mathrm{~mm}$ \\
\hline Total displacement & $1.3 \mathrm{dm}^{3}$ \\
\hline Compression ratio & 16.8 \\
\hline Maximum power & $55 \mathrm{~kW} / 4000 \mathrm{rpm}$ \\
\hline Maximum torque & $200 \mathrm{~N} \cdot \mathrm{m} / 1500 \mathrm{rpm}$ \\
\hline
\end{tabular}

In order to evaluate the operating points for which the control task will be performed, a road tests of a vehicle equipped with such engine in conditions of real road traffic have been planned and accomplished. A number of drives were performed within framework of the tests, the cars were driven both in urban traffic conditions and on extraurban roads. Parameters of vehicle's motion, engine speed and degree of engine load were recorded during the tests comprising in total eight hours of the driving. The recording was carried out with use of computer connected to OBD system of tested car. Read-out of motion parameters with frequency $1 \mathrm{~Hz}$ was performed with use of ELM327 Interface (OBD $\rightarrow$ RS232 Interpreter) and authorial software enabling simultaneous archiving of data downloaded from engine's ECU. All operating points of the engine recorded in course of the performed road tests [1] are presented in the Fig. 1.

Analysis of the road test results is pointing at dominating range of engine speed from interval of 2000-3000 rpm, and engine loads up to $75 \%$ of maximal torque at a given rotational speed. On this basis, four different engine loads for rotational speed of $2500 \mathrm{rpm}$ have been chosen as the points for which the control task was solved. Summary of analyzed operating points from the control task presented in this study is given in the Table 2. Therefore, selected points of engine operation correspond to conditions often found in real conditions of engine operation.

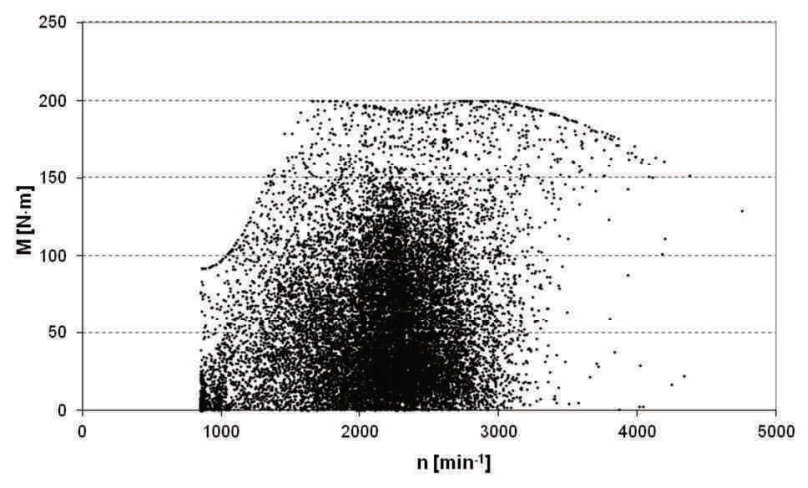

Fig. 1. Operating points of the engine recorded during accomplished road tests

Table 2. The engine's operating points considered in the control task

\begin{tabular}{|c|c|c|c|c|}
\hline Load & $\begin{array}{c}0.25 \\
\mathrm{M}_{\max (2500 \mathrm{rpm})}\end{array}$ & $\begin{array}{c}0.50 \\
\mathrm{M}_{\max (2500 \mathrm{rpm})}\end{array}$ & $\begin{array}{c}0.75 \\
\mathbf{M}_{\max (2500 \mathrm{rpm})}\end{array}$ & $\begin{array}{c}0.90 \\
\mathbf{M}_{\max (2500 \mathrm{rpm})}\end{array}$ \\
\hline Torque & $48 \mathrm{~N} \cdot \mathrm{m}$ & $95 \mathrm{~N} \cdot \mathrm{m}$ & $143 \mathrm{~N} \cdot \mathrm{m}$ & $171 \mathrm{~N} \cdot \mathrm{m}$ \\
\hline
\end{tabular}

Evaluation of permissible emissions of a given compound, and thus imposing limitations assumed in the control task, require analysis of exhaust gases' level emitted by tested engine, with respect to emission levels from other compression ignition engines, having comparable performance and displacement. Similarly, making benchmarking it is possible to define limitations related to thermal efficiency, mechanical and thermal engine loads. In this way the coefficients values present in the constraints (15-18) and shown in the Table 3 were evaluated.

Table 3. Values of coefficients $\delta_{i}, \gamma, \zeta_{\mathrm{i}}$ taken to definition of boundary conditions in the control task

\begin{tabular}{|c|c|c|c|c|c|}
\hline$\delta_{\mathrm{CO}}$ & $\delta_{\mathrm{HC}}$ & $\delta_{\mathrm{D}}$ & $\gamma$ & $\zeta_{\mathrm{P}_{\max }}$ & $\zeta_{\mathrm{T}_{\max }}$ \\
\hline 1.3 & 1.2 & 1.5 & 0.95 & 1.1 & 1.1 \\
\hline
\end{tabular}

The Nelder-Mead method (downhill simplex method) was used to solve optimization task of the form with limitations. As result of performed optimization computations, new vectors of adjusting parameters were evaluated for each from analyzed operating points. Comparison with the parameters corresponding to factory settings is shown in the Table 4.

Table 4. Factory parameters and optimum parameters

\begin{tabular}{|l|c|c|c|c|}
\hline \multirow{4}{*}{$\begin{array}{l}\text { Factory settings } \\
\mathrm{X}_{0}\end{array}$} & Engine load & $\mathrm{B}_{0}[\mathrm{~g}]$ & $\begin{array}{c}\varphi_{\mathrm{w}} \\
{\left[{ }^{\circ} \mathrm{OWK}\right]}\end{array}$ & $\begin{array}{c}\mathrm{X}_{\text {EGR }} \\
{[\%]}\end{array}$ \\
\cline { 2 - 5 } & $0.25 \mathrm{M}_{\max }$ & $0.9790 \cdot 10^{-2}$ & 356 & 20 \\
\cline { 2 - 5 } & $0.50 \mathrm{M}_{\max }$ & $1.7213 \cdot 10^{-2}$ & 354.4 & 11 \\
\cline { 2 - 5 } & $0.75 \mathrm{M}_{\max }$ & $2.4490 \cdot 10^{-2}$ & 353 & 0 \\
\cline { 2 - 5 } & $0.90 \mathrm{M}_{\max }$ & $2.8907 \cdot 10^{-2}$ & 352.5 & 0 \\
\hline \multirow{2}{*}{$\begin{array}{l}\text { Settings evaluated } \\
\text { for assumed objec- } \\
\text { tive function (13) } \\
\mathrm{X}_{\text {OPT }}\end{array}$} & $0.25 \mathrm{M}_{\max }$ & $1.0769 \cdot 10^{-2}$ & 356.6 & 24 \\
\cline { 2 - 5 } & $0.50 \mathrm{M}_{\max }$ & $1.729 \cdot 10^{-2}$ & 357.8 & 11 \\
\cline { 2 - 5 } & $0.75 \mathrm{M}_{\max }$ & $2.4561 \cdot 10^{-2}$ & 354 & 0 \\
\cline { 2 - 5 } & $0.90 \mathrm{M}_{\max }$ & $2.895 \cdot 10^{-2}$ & 353.6 & 0 \\
\hline
\end{tabular}


Use of calculated adjustment parameters $\mathbf{X}_{\mathrm{OPT}}$ leads to changes in the emissions (Table 5) and simultaneously satisfies, with sufficiently big margin, accepted limitations imposed on allowable changes in characteristic points of the working cycle.

Analysis of the data summarized in the Table 5 confirms possibility of significant reduction of emissions of nitrogen oxides, up to about $30 \%$ depending on point of engine operation, with simultaneous maintaining of assumed limitations with respect to other harmful compounds of exhaust gases and smokiness. Comparison of the values of medium indicated pressure, thermal efficiency of the working cycle, maximal pressure and temperature of the working cycle, obtained for factory set adjusting parameters, and after the modification, are presented in the Fig. 2.
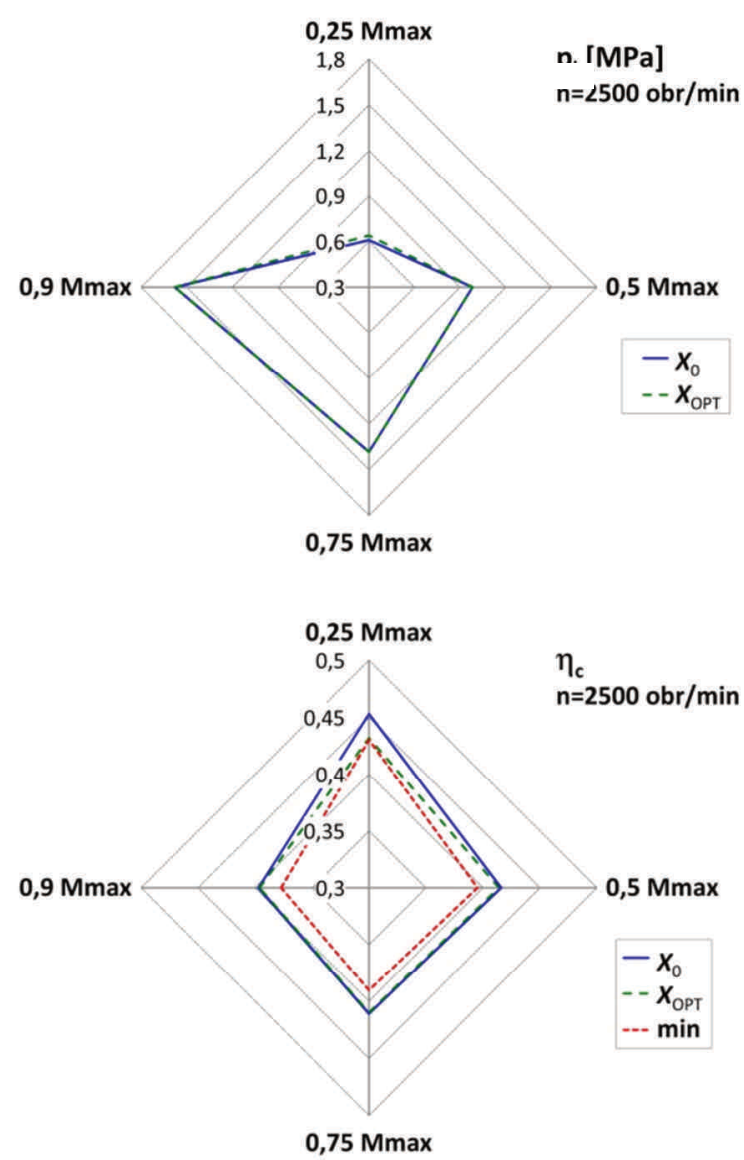

Table 5. Emissions of harmful exhaust gases in analyzed points of engine operation

\begin{tabular}{|c|c|c|c|c|c|}
\hline & Engine load & $\begin{array}{c}\mathrm{F}_{\mathrm{CO}} \\
{[\%]}\end{array}$ & $\begin{array}{c}\mathrm{F}_{\mathrm{HC}} \\
{[\mathrm{ppm}]}\end{array}$ & $\begin{array}{c}\mathrm{F}_{\mathrm{NO}_{\mathrm{x}}} \\
{[\mathrm{ppm}]}\end{array}$ & $\begin{array}{c}\mathrm{F}_{\mathrm{D}} \\
{[\mathrm{FSN}]}\end{array}$ \\
\hline \multirow{4}{*}{$\begin{array}{c}\text { Factory settings } \\
\mathbf{X}_{0}\end{array}$} & $0.25 \mathrm{M}_{\max }$ & 0.068 & 265 & 97 & 0.3 \\
\cline { 2 - 6 } & $0.50 \mathrm{M}_{\max }$ & 0.017 & 80 & 253 & 0.8 \\
\cline { 2 - 6 } & $0.75 \mathrm{M}_{\max }$ & 0.007 & 50 & 769 & 0.2 \\
\cline { 2 - 6 } & $0.90 \mathrm{M}_{\max }$ & 0.007 & 44 & 898 & 0.2 \\
\hline \multirow{2}{*}{$\begin{array}{c}\text { Settings evalu- } \\
\text { ated for as- } \\
\text { sumed objec- } \\
\text { tive function } \\
(13) \mathbf{X}_{\text {OPT }}\end{array}$} & $0.25 \mathrm{M}_{\max }$ & 0.089 & 303 & 70 & 0.36 \\
\cline { 2 - 6 } & $0.50 \mathrm{M}_{\max }$ & 0.021 & 74 & 175 & 1.21 \\
\cline { 2 - 6 } & $0.90 \mathrm{M}_{\max }$ & 0.009 & 48 & 697 & 0.24 \\
\hline \multirow{2}{*}{\begin{tabular}{c} 
and \\
\cline { 2 - 6 }
\end{tabular}} & 0.008 & 43 & 812 & 0.28 \\
\hline
\end{tabular}

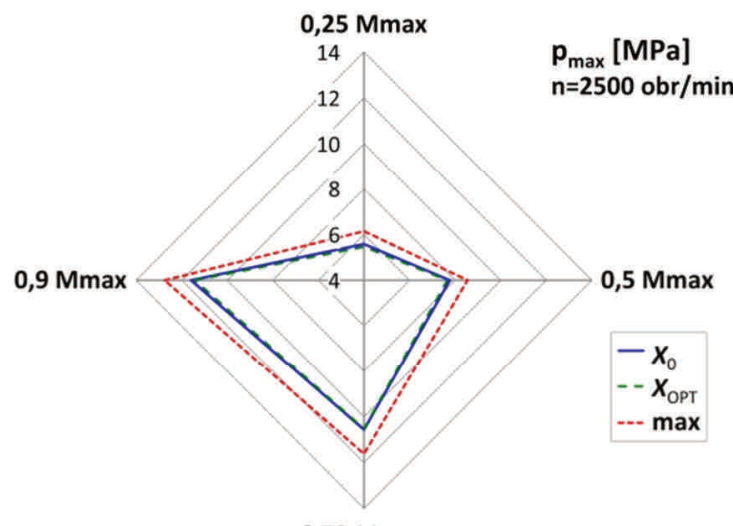

$0,75 \mathrm{Mmax}$

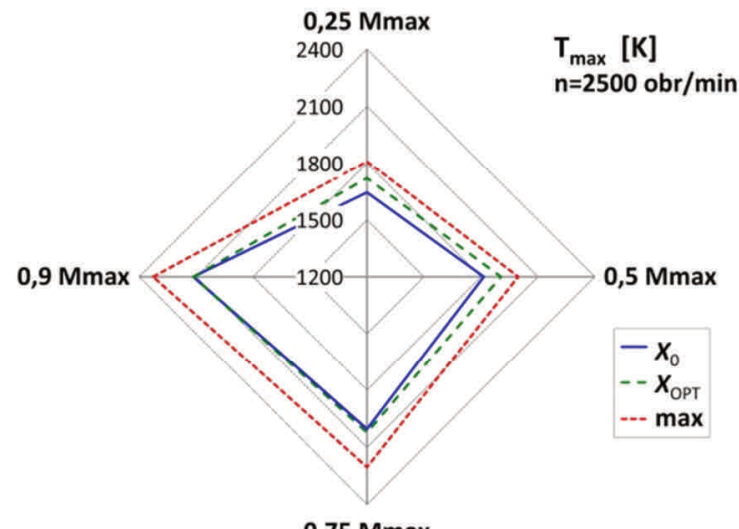

0,75 Mmax

Fig. 2. Values of medium indicated pressure, thermal efficiency of working cycle, maximal pressure and temperature of the working cycle after application of calculated adjusting parameters $\mathbf{X}_{\mathbf{O P T}}$ in relation to values of factory settings $\mathbf{X}_{\mathbf{0}}$

\section{Conclusions}

Obtained solutions of the task aimed at selection of adjusting parameters in selected points of engine operation, obtained due to criterion of minimization of nitrogen oxides emission can be assessed on the basis of many criteria, which can be grouped within framework of three cumulative categories:

- environmental impact (emission of individual compounds of exhaust gases),
- utility (overall efficiency of the cycle),

- requirements of durability (maximal pressure and maximal temperature in the cylinder).

Due to significant environmental burden of harmful emissions of exhaust gases from traction vehicles, and taking into account increase in fleet of road going vehicles, the environmental criterion can be assumed as absolutely dominant over criterion of durability, and significantly preferred over criterion representing utility. 


\section{Nomenclature}

$\mathbf{X} \quad$ vector of control parameters

$\mathrm{X}_{\mathrm{EGR}}$ degree of exhaust gas recirculation

E vector of model parameters

G vector of auxilary parameters

$\varphi_{\mathrm{w}} \quad$ injection advance angle

$\varphi \quad$ crank angle

$\mathrm{m}$ mass of the medium in cylinder

$\mathrm{p} \quad$ pressure in cylinder

$\mathrm{T}$ temperature in cylinder

\section{Bibliography}

[1] ADAMSKI, W., BRZOZOWSKI, K., NOWAKOWSKI, J., PRASZKIEWICZ, T. Rzeczywista eksploatacja trakcyjna silnika a warunki przyjmowane w teście homologacyjnym. Autobusy. Technika, Eksploatacja, Systemy Transportowe. 2014, 5, 37-40.

[2] BRZOZOWSKI, K., NOWAKOWSKI, J. Model for calculating compression ignition engine performance. Eksploatacja i Niezawodnosc - Maintenance and reliability. 2014, 3, 407-414.

Jacek Nowakowski, DSc., DEng. - Department of Combustion Engines and Vehicles at Faculty of Mechanical Engineering and Computer Science at University of Bielsko-Biala.

e-mail:JNowakow@ath.bielsko.pl

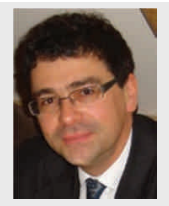

Krzysztof Brzozowski, DSc., DEng. - Department of Transport at Faculty of Management and Transport at University of Bielsko-Biala.

e-mail: KBrzozowski@ath.bielsko.pl
[3] BRZOZOWSKI, K., NOWAKOWSKI, J. Toxicity of exhaust gases of compression ignition engine under conditions of variable load for different values of engine control parameters. Eksploatacja i Niezawodnosc - Maintenance and Reliability. 2011, 4, 56-62.

[4] HEYWOOD, J.B. International combustion engine fundamentals. New York: Mc-Graw-Hill, 1988.

[5] KNEFEL, T. Problematyka kształtowania sygnału sterującego wtryskiwaczem zasobnikowego układu zasilania w paliwo. Wydawnictwo Naukowe Akademii Techniczno-Humanistycznej, Bielsko-Biala, 2013.

Tomasz Knefel, DSc., DEng. - Department of Combustion Engines and Vehicles at Faculty of Mechanical Engineering and Computer Science at University of Bielsko-Biala.

e-mail:TKnefel@ath.bielsko.pl

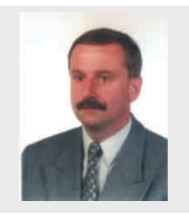

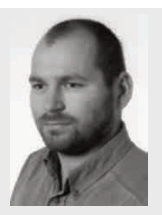

